\title{
A INFLUÊNCIA DA FAMÍLIA NA ESCOLHA DA CARREIRA: UMA ANÁLISE DO GENOPROFISSIOGRAMA DE DOCENTES DA UNIPAMPA
}

\author{
Carolina Freddo Fleck \\ Universidade Federal do Pampa - UNIPAMPA (Brasil) \\ carolinafleck@unipampa.edu.br.https://orcid.org/0000-0002-1595-0100 \\ Akila Miranda Pereira Buarque dos Montes Silva \\ Universidade Federal do Pampa - UNIPAMPA (Brasil) \\ Michelle Castanho Machado \\ Universidade Federal do Pampa - UNIPAMPA (Brasil) \\ https://orcid.org/0000-0002-0569-6639
}

\begin{abstract}
Resumo. Esta pesquisa teve como objetivo analisar a influência que a árvore genealógica profissional tem na escolha da carreira de docentes da Universidade Federal do Pampa, no campus de Santana do Livramento. Optou-se por analisar os educadores como forma de reconhecer a importância que possuem, pois são indispensáveis na construção do saber. A partir da elaboração do genoprofissiograma, com o auxílio de entrevistas semiestruturadas, foi possível observar o percurso profissional realizado pelos indivíduos a partir de preferências durante a infância e a adolescência, suas opções de curso universitário e a escolha efetiva da carreira docente. Além disso, identificou-se quais membros da família se mostraram mais relevantes durante esse período e fez-se uma reflexão acerca desse processo.
\end{abstract}

Palavras-chave: Carreira docente. Genoprofissiograma. Escolha profissional. Família.

\section{THE FAMILY INFLUENCE ON CAREER'S CHOICE: AN ANALYSIS OF THE GENOPROPHYSIOGRAM OF UNIPAMPA'S TEACHER}

\begin{abstract}
This research aimed to analyze the influence of the professional genealogical tree on the career choice of professors of the Federal University of Pampa, in the campus of Santana do Livramento. Were analyzed educators as a way of recognizing the importance they have, since they are indispensable in the construction of knowledge. Through the elaboration of the genoprofissiograma, with the aid of semi- structured interviews, it was possible to observe the professional course of the individuals from preferences during childhood and adolescence, options of university course, ending with the effective choice of the teaching career. It was also possible to identify which family members were most relevant during this time and bringing a reflection about this process.
\end{abstract}

Keywords: Teaching career. Genoprofissiograma. Choose professional. Family.

\section{INFLUENCIA FAMILIAR EN LA ELECCIÓN DE CARRERA: UN ANÁLISIS DEL GENOPROFISIOGRAMA DE PROFESORES DE UNIPAMPA}

Resumen. Esta investigación tuvo por objetivo analizar la influencia que el árbol genealógico profesional tiene en la elección de la carrera de docentes de la Universidad Federal del Pampa, en el campus de Santana do Livramento. Se optó a analizar a los educadores como una forma de reconocer la 
importancia que poseen, pues se hacen indispensables en la construcción del saber. A través de la elaboración del genoprofisiograma, con ayuda de entrevistas semiestructuradas, fue posible observar el recorrido profesional realizado por los individuos a partir de preferencias durante la infancia y adolescencia, opciones de curso universitario, finalizando con la elección efectiva de la carrera de docente. Identificando qué miembros de la familia se mostraron más relevantes durante este período y trayendo una reflexión acerca de este proceso.

Palabras-clave: Carrera docente. Genoprofissiograma. Elección profesional. Familia.

\section{Introdução}

Uma das fases mais complexas na vida de um indivíduo é o momento em que se faz necessário escolher a carreira que irá seguir. Isso acontece porque é preciso que sejam trabalhados aspectos associados ao autoconhecimento, ou seja, o indivíduo precisa conhecer a si mesmo, determinar seu projeto de vida e como ele se analisa doravante desempenhando o seu trabalho.

O início dessa caminhada ocorre durante a adolescência, quando o jovem pode ver essa decisão como uma escolha definitiva, considerando-se que diversas pessoas seguem pela mesma profissão durante toda vida. Nessa fase, acontecem diversas transições que vão consolidar sua personalidade. Schoen-Ferreira, Aznar-Farias e Silvares (2003) afirmam que a construção da identidade não se limita a um período cronológico, mas a uma série de tarefas que devem ser cumpridas, entre elas as relacionadas à carreira e independência financeira. Os resultados destes estudos indicam que o que mais afligiu os jovens foi a incapacidade de definir uma identidade ocupacional.

Muitos estudos encontrados (Aguiar, 2006, Almeida e Melo-Silva, 2011, Veriguine e outros, 2010, Santos, 2005, Nogueira, 2004) associavam-se à escolha na adolescência, mas escassas foram as pesquisas que refletiam sobre a escolha na vida adulta. Essa escassez motivou esta pesquisa a realizar tal reflexão com indivíduos que já percorreram esse trajeto e se encontram estabilizados na profissão selecionada.

De acordo com Freitas e Barbosa (2006), diversos fatores influenciam na escolha da profissão, uma vez que ela pode estar predeterminada pela família, por meios de comunicação em massa e pela estrutura educacional. Os autores indicam que a família é um dos elementos principais que auxiliam ou obstaculizam o momento da escolha e das decisões, posto que todo indivíduo faz parte de uma família que possui uma história e características distintas.

Nesse sentido, o presente estudo tem como escopo analisar, especificamente, o processo de escolha da profissão docente, pois a importância desempenhada por esses profissionais assume um papel vital na sociedade, onde a educação tem se mostrado como a única alternativa viável para promover uma maior conscientização social, política e econômica, pois, conforme Freire (2000, p. 67) "se a educação sozinha, não transforma a sociedade, sem ela tampouco a sociedade muda". Assim, o objetivo foi analisar a influência que a árvore genealógica profissional tem na escolha da carreira de docentes da Universidade Federal do Pampa, no campus de Santana do Livramento.

O momento da escolha de carreira é de suma importância na vida de um indivíduo. Entende-se, portanto, que seja útil que pesquisas sejam realizadas, a fim de ampliar o entendimento do processo de escolha profissional. Desse modo, esse estudo se justifica pela importância de viabilizar um instrumento que facilite esse processo, tanto para quem for escolher a carreira quanto para facilitar a aceitação dessa escolha. Tanto por parte dos familiares, que são sustentáculos na formação dos princípios e 
valores dos indivíduos, quanto pelas universidades, que, em um primeiro momento, atuam diretamente na formação profissional do indivíduo. E, posteriormente, podem vir a ser o ambiente de trabalho daqueles que optaram pela carreira de docente. Este estudo se justifica, ainda, para que os resultados aqui reunidos possam no futuro servir de base para outros estudos que venham a abordar o mesmo tema.

De acordo com Soares (2002), quando se pensa em carreira, é necessário observar a totalidade do "eu", num sentido de considerar o que fomos, as influências que tínhamos na infância e que modelaram quem nos tornamos, os fatos mais significativos e marcantes até o presente momento e o estabelecimento de um estilo de vida preferido. A consideração desses elementos facilita o processo de escolha profissional, e isso irá viabilizar ou não a realização de nossas expectativas.

Conforme Luft, Boaventura e Colombo (2015), as circunstâncias que se associam ao processo de escolha profissional são pesarosas e desafiam a maior parte dos indivíduos. Os próprios valores e concepções culturais disseminados no ambiente social em que vivemos acabam fazendo com que essa decisão, fundamentalmente, seja tomada no período da adolescência. Nesse momento, incontáveis são as inseguranças e incertezas que gravitam ao redor do indivíduo, pois ele imprime nas pessoas a urgência de encontrar respostas e definições para esse momento da vida e também para o futuro. Assim, não bastam todas as transformações com que o adolescente precisa lidar, surge ainda essa necessidade de escolha profissional.

Em pesquisa realizada por Tonn, Geremia e Schweitzer (2015) com jovens que com idade entre 15 e 19 anos, estudantes de um curso técnico, constatou-se que o aumento da idade dos participantes era diretamente proporcional à evolução da maturidade para sua escolha profissional.

Independentemente de não possuírem maturidade e, por vezes, não compreenderem os fatores que são determinantes para suas escolhas, os indivíduos necessitam definir que carreira seguir. Soares (2002) afirma que, no instante em que o indivíduo decide seu futuro, muitas vezes não tem uma percepção muito apurada de como esse fato está inserido dentro de um contexto mais amplo, da ideologia subjacente a qualquer sistema político e social que existe. Na maior parte das vezes, ele não possui ciência da maneira como se desenrolam as relações sociais e de trabalho no meio em que vive.

Além disso, a ausência de entendimento sobre as carreiras disponibilizadas revela o quanto os debates propostos pelos centros educacionais sobre o mercado de trabalho ainda são pequenos, tímidos e insatisfatórios. Ao se pressupor que essa é uma tarefa predominantemente da família e da sociedade, acaba-se excluindo a responsabilidade que a própria escola tem de discutir e orientar acerca de tais assuntos (Luft, Boaventura e Colombo, 2015). O trabalho de Veriguine e outros (2010) é uma exceção e demonstra que também na universidade se debate o futuro da carreira e a inserção no mercado de trabalho. Esse trabalho demonstra a importância do autoconhecimento sobre o que se espera e como é possível se preparar para esse mercado. Nesse contexto, a influência da família é reforçada, uma vez que as escolhas já impactadas por ela, conforme estudos anteriores já demonstraram, serão reafirmadas nas reflexões dentro da universidade.

Cada indivíduo possui uma maneira única de enxergar o mundo, e as primeiras experiências que o ser humano adquire são tidas no âmbito familiar. Neuburger (1999) define família como uma estrutura prática que disponibiliza conforto e higiene. Na concepção de família existe uma estruturação organizada que é ligada por um "cimento", sendo este responsável pela formação da identidade do grupo, o que permite diferenciar uma unidade, ou família, da outra e do ambiente externo. Esse cimento é o 
mito familiar. Pode-se dizer que o mito "é a crença mostrada em características, especificidades do grupo. Essas crenças concernem todos os níveis de realidade da família, o conjunto dessas crenças constitui a "personalidade" de uma família, o mito de uma família" (Neuburger, 1999, p. 14-15).

Segundo Paccola (1994), o mito desenvolve em sua parte mais basilar a compreensão acerca do mundo, a partir do que a família vive, onde se forma, organizando essa percepção em uma escala coletiva, por intermédio da vida familiar, para posteriormente organizar-se individualmente, a partir das próprias convicções e valores. Em relação ao surgimento do mito, Paccola (1994) aponta diversas particularidades que desempenham o papel de possibilitar a trama mítica: desde a integração de mitos culturais, que conduz a uma atitude extensa de aceitação, até o aparecimento de segredos, que podem se tornar influenciadores ou serem influenciados pelo aparecimento dos mitos.

Ainda de acordo com a autora, um conceito associado à trama mítica é a lealdade multipersonal, ou lealdades invisíveis, que faz com que exista uma expectativa do grupo de que todos os membros da família assumam um compromisso. Assim, Filomeno (2003, p. 56) afirma que "todo ser humano tem uma missão familiar a cumprir, explícita ou implícita, grande ou pequena, possível ou impossível”.

De acordo com uma pesquisa feita por Santos (2005), pode-se verificar que, ainda que o adolescente faça seu planejamento, buscará o apoio inicial na família. Os pais, na maior parte das vezes, são os responsáveis financeiros pelos custos associados direta ou indiretamente ao ensino superior. Além do suporte financeiro, normalmente é na família que o adolescente encontra também o suporte emocional para a execução, o desenvolvimento e a realização de seu projeto. Almeida e MeloSilva (2011, p. 82) afirmam que:

A influência envolve tanto ações objetivas e práticas, como intervenções dos pais proporcionando: apoio financeiro, formação educacional, diálogos/ações facilitadoras da exploração vocacional; como também influências de ordem subjetiva, nem sempre tão claras e, por vezes, inconscientes, como: apoio, aprovação/reprovação das escolhas, expectativas de resultados, cobranças e, até mesmo, influências dos estilos de interação familiar, valores/crenças dos pais sobre mundo do trabalho, suas problemáticas vocacionais, sonhos e projetos que mantêm para os filhos, dificuldades no processo de separação pais-filhos, dentre outros. Todas essas variáveis de influência atuam, possibilitando ou mesmo limitando o desenvolvimento vocacional dos filhos e, mais particularmente, o processo da escolha da carreira.

Dessa forma, Santos (2005) explica que a família exerce uma grande influência no projeto de vida do indivíduo porque, geralmente, é nela que esse projeto se inicia e é por intermédio dela que o jovem "sai" em busca da concretização de seus "sonhos". Em sua pesquisa, o mesmo autor verificou que, por causa dessa dependência da família, existia uma certa dificuldade por parte de muitos jovens para enfrentá-la caso a escolha feita não fosse a esperada pelos familiares.

Aguiar (2016) afirma que essa decisão pode ser mais do que apenas uma escolha de carreira, podendo se constituir como um projeto pessoal. Esse projeto, que é integrado por meio de relações históricas e sociais, dessa maneira, pode ainda se constituir como um projeto mais amplo de transformação social.

Nogueira (2004) indica que, possivelmente, a percepção que os indivíduos têm de si mesmos, das demais pessoas e da realidade em geral influencia diretamente na escolha de seus cursos de formação, em especial na graduação. Desse modo, a questão basilar é entender como esse conjunto de concepções se configura, se sustenta e se 
modifica ao longo dos anos. Do mesmo modo, a escolha pela docência, conforme Deimling e Reali (2017, p. 7), é "influenciada pelas experiências pessoais, acadêmicas e profissionais vivenciadas antes e depois da formação".

De acordo com Almeida, Tartuce e Nunes (2010), para que sejam abordados os aspectos associados à atratividade da carreira docente, é necessário ter em mente que os processos que se relacionam à escolha da profissão e à inserção no mercado de trabalho possuem cada vez mais complexidade. Assim, as oportunidades de escolha profissional não se associam apenas às características individuais, mas, essencialmente, ao ambiente e contexto em que o indivíduo vive. Cabe destacar que os aspectos relacionados ao salário não abarcam a totalidade dos questionamentos relativos à atratividade profissional.

Almeida e outros (2010) apontam ainda que o planejamento profissional é resultado dos fatores intrínsecos e extrínsecos, ou seja, tal projeto é feito após a análise do contexto em que se vive. Levam-se em consideração elementos como empregabilidade, renda, status gerado pela carreira, grau de identificação com a carreira, competências, habilidades, princípios, maturidade, a própria personalidade e o que se espera em relação ao futuro.

Fanfani (2005) afirma que determinadas profissões possuem a tendência de serem transmitidas entre as gerações. Salienta-se, entretanto, que essa transmissão não ocorre de maneira evidente e formal, mas de modo informal e indefinido, contudo ela é fidedigna ou idêntica às demais heranças culturais. Esse evento ocorre com maior frequência nas sociedades tradicionais.

Fanfani (2005) ainda verificou em sua pesquisa, realizada na Argentina, no Brasil, no Peru e no Uruguai, que a carreira docente é fortemente hereditária, pois ela comumente se reproduz dentro das configurações familiares. O resultado disso é que quase metade dos professores mencionou possuir algum familiar que desempenha a mesma profissão. Dentre os países pesquisados, esse fato ocorre com menor incidência no Uruguai, contudo é da mesma forma importante. No Brasil e no Peru, mais de um terço dos entrevistados declarou que possuía um irmão ou uma irmã docente. Aproximadamente entre 15 e $20 \%$ dos indivíduos entrevistados nesses países declararam que possuíam mãe e pai docentes, além disso cerca de $10 \%$ das pessoas alegaram possuir a mesma profissão do seu cônjuge. No Peru, em 17,7\% dos casos investigados, os docentes também têm cônjuge docente.

Segundo pesquisa realizada por Nogueira, Almeida e Queiroz (2010), o incentivo dado pelo núcleo familiar demonstrou estar associado ao grau de instrução dos entrevistados. Aproximadamente $83 \%$ dos familiares dos entrevistados que cursaram o Ensino Fundamental em escolas públicas apoiaram sua escolha por cursos de graduação voltados para a docência, esse percentual cai para $64 \%$ no caso de entrevistados que fizeram o Ensino Fundamental em escolas particulares.

Tais dados confirmam que pais e familiares que possuem um nível socioeconômico mais elevado têm uma expectativa maior em relação à remuneração salarial, não se satisfazendo com escolhas associadas à docência, em virtude da desvalorização salarial que a profissão enfrenta. Gatti (2012) aponta que os valores recebidos pelos professores não são equivalentes ao nível de formação necessário para lecionar, às responsabilidades e à jornada de trabalho. Fanfani $(2005$, p. 64) também apurou que

a herança do ofício ocorre mais frequentemente entre os docentes que possuem uma idade mais avançada. Tal fato pode ser elucidado por duas razões. A probabilidade é maior de ter irmãos que já entraram no mercado de trabalho, quando se tem uma idade avançada, assim como a possibilidade de ter um 
cônjuge docente ocorre com mais frequência nas gerações mais adultas. Ao analisar esses dados, pode-se argumentar que o fenômeno da hereditariedade profissional tende a diminuir com o tempo.

Deimling e Reali (2017) apontam que os fatores que mais desmotivam os estudantes, atualmente, a seguirem carreira na área do magistério estão associados com a inexistência de condições de trabalho apropriadas, as funções e responsabilidades outorgadas em demasia e a crescente desvalorização financeira e social da profissão em detrimento de outras profissões nas quais é necessário ter o mesmo nível de escolarização. Assim, a partir do conhecimento das motivações para a escolha da carreira, como a influência da família e dos mitos, o docente poderá compreender se fez a escolha mais ajustada.

\section{Método}

Esta pesquisa consiste em um estudo exploratório-descritivo de abordagem qualitativa. $\mathrm{O}$ método da pesquisa foi o Estudo Narrativo, com o uso do genoprofissiograma como técnica de coleta de dados. O estudo narrativo é um método adequado para estudos qualitativos com populações pequenas, pois utiliza apenas uma técnica de coleta de dados (Creswell, 2014).

Identificou-se que a melhor forma de obter as informações necessárias seria com um genoprofissiograma, ou árvore genealógica profissional da família, porque essa técnica permite ao participante a reflexão sobre a trajetória profissional de sua família. O genoprofissiograma foi associado ao uso de entrevista semiestruturada, em que se utilizou como base o roteiro de entrevista da pesquisa de Bueno (2013), com as adaptações necessárias para o contexto estudado.

O primeiro passo foi a organização do genoprofissiograma. Conforme Filomeno (2003), solicita-se que a pessoa faça sua árvore genealógica, indicando as escolhas profissionais de seus pais, avós, bisavós, irmãos e primos, tanto do lado materno quanto do lado paterno da família. Ao desenhar o genoprofissiograma, podese visualizar o papel exercido pela família na escolha profissional e analisar as redes relacionais formadas.

Após o desenho do genoprofissiograma, foram realizadas entrevistas semiestruturadas, com foco em permitir aos entrevistados uma reflexão sobre a trajetória profissional da família e a influência desta na sua própria trajetória.

Os sujeitos-alvos desta pesquisa foram compostos, inicialmente, por dez docentes da Universidade Federal do Pampa, do campus de Santana do Livramento. Foram convidados a participar dois docentes de cada curso, a saber, Administração, Ciências Econômicas, Direito, Gestão Pública e Relações Internacionais, como forma de tornar mais abrangente a análise da pesquisa. De acordo com a disponibilidade, obteve-se efetivamente a participação de nove docentes. A escolha pelos sujeitos da pesquisa atendeu o quesito de conveniência e disponibilidade dos participantes. $\mathrm{Na}$ análise dos dados os mesmos estão apresentados com nomes fictícios escolhidos pelos próprios entrevistados no dia em quem foram conduzidas as entrevistas.

A técnica utilizada para a análise de dados foi a análise interpretativa. A função da interpretação "é explorar as interconexões entre o significado mobilizado pelas formas simbólicas e as relações de dominação que este significado pode fortalecer em contextos específicos" (Thompson, 2011, p. 410).

\section{Análise dos dados}

Nesta seção, são descritos e interpretados os conteúdos abordados nas entrevistas acerca das unidades temáticas que caracterizam a presente pesquisa. Os sujeitos que 
participaram da pesquisa tiveram seus nomes mantidos em sigilo. Destarte, foram categorizados de acordo com nomes fictícios previamente escolhidos por eles, a saber: Aimêe, Cecília, Charles Darwin, Hannah, Hans Morgenthau, Maria, Marthina, Peter Quill e Princesa Sophia.

A entrevista foi elaborada a partir dos tópicos desta pesquisa, sendo dividida em quatro blocos: a escolha da carreira, a influência da família na escolha da carreira, a carreira docente e a construção do genoprofissiograma. Todas as entrevistas realizadas tiveram seus dados transcritos e foram realizadas pequenas correções relacionadas a vícios de linguagem e erros linguísticos, a fim de que a leitura possa fluir melhor na apresentação dos resultados.

\section{- A escolha da carreira}

Ao indagar os entrevistados acerca do que as pessoas devem considerar ao escolherem sua profissão, eles foram unânimes ao responder que é indispensável buscar algo com que a pessoa se identifique, mas também ponderar acerca das oportunidades oferecidas pelo mercado de trabalho, a fim de atingir um nível razoável de satisfação pessoal. Na visão dos entrevistados, ao escolher uma carreira, não apenas a aptidão natural para atuar naquela área deve ser levada em consideração, mas também a maneira com que as oportunidades são distribuídas. Sobre isso, o entrevistado Hans Morgenthau afirma:

Idealmente as pessoas devem considerar o que elas gostam, o que elas se sentem bem fazendo. No mundo real elas devem considerar uma série de fatores. Primeiro, se é possível elas seguirem aquela profissão imediatamente, se aquilo vai dar o retorno que ela espera e que escolhas ela de fato tem. Isso é até um pouco cruel de falar às vezes, mas infelizmente a gente vive numa ideia de que a pessoa pode fazer o que ela quiser. De novo, o ideal seria isso, mas infelizmente poucas pessoas têm o privilégio de fazer o que elas querem. Se você tem a possibilidade de fazer o que você quer, eu recomendaria pra você que leve em consideração aquilo que te dá prazer, aquilo que te dá significado, que você acorda todo dia e sabe que isso faz a diferença e que bom que isso é pra mim e para os outros. Se você não tá nessa situação, que é a situação da maioria das pessoas, eu acho que seria interessante sopesar o que é possível fazer sem perder o seu sonho de vista. O que dá pra fazer nesse momento, é agora, o meu sonho é aquele lá, mais pra frente. Como eu posso fazer dado que minha situação é essa? Para navegar e chegar de forma realista até lá.

Tal compreensão aparece no pensamento de Soares (2002) sobre ser importante escolher aquilo que queremos ser e fazer no futuro, posto que a carreira profissional que iremos desempenhar irá possibilitar ou não a realização de nossas expectativas.

Para o entrevistado supracitado, muitas pessoas não possuem o privilégio de fazer aquilo que realmente querem, então a decisão precisa ser tomada de uma maneira bem realista. Do ponto de vista de Valle (2006), diferentemente do que o senso comum acredita, o destino de uma pessoa não se forma por meio das características individuais de sua personalidade, mas advém essencialmente do fato de ter sido gerado numa determinada época e num determinado contexto social e cultural, delimitado por elementos estruturais bem definidos nas esferas educacional, econômica e política. Tais noções refletem as opções que cada um possui e acabam organizando o futuro no que há de mais amplo nesse termo, encaminhando a escolha da profissão e influenciando grandemente o percurso profissional.

Embora a decisão sobre a escolha da carreira seja tomada, muitas vezes, na juventude, é necessário que a integralidade do "eu" seja observada, levando-se em 
consideração o que fomos, as experiências que tivemos, desde a mais tenra idade, e que acabaram modelando quem nos tornamos e os sonhos que possuímos hoje. Quando questionada acerca da carreira que gostaria de seguir quando era criança, a entrevistada Princesa Sophia mencionou que:

Ai, eu não lembro muito bem... mas... Eu gostava de ser médica, eu lembro que toda vez que acontecia alguma coisa com meu pai, eu sempre era a médica dele. E gostava muito de trabalhar em escritório, papel, preencher alguma coisa e brincava de professora, lógico! Filha de professora tinha que brincar de professora. Então tinha quadro, dava aula, dei muitas aulas para os meus alunos fictícios, eram essas três e no fim acabei sendo uma delas, né?

Soares (2002) afirma que, no instante em que o indivíduo decide seu futuro, muitas vezes não tem uma percepção muito apurada de como esse fato está inserido em um contexto mais amplo, na ideologia subjacente a qualquer sistema político e social que existe.

Para a entrevistada Maria, a escolha da carreira ocorreu de uma maneira bem natural, uma vez que desde criança ajudava seu pai na empresa da família. Foram essas experiências acumuladas que modelaram o que ela gostaria de se tornar, uma administradora:

Meu pai tem uma empresa há 45 anos mais ou menos. E é uma empresa do ramo de alimentação. Ele já teve seis lojas, hoje ele tem duas só. E eu comecei a trabalhar na empresa com 7 anos, então assim sabia fazer tudo, eu atendia no caixa, eu dava troco, eu aprendi matemática dando troco. Eu e minha irmã nas férias a gente sempre trabalhou. Em função disso, começou a surgir a questão da administração, né? Então, eu fui criada dentro da empresa, e administração na adolescência começou a surgir como uma opção de formação. Assim, eu acho que desde a $8^{\text {a }}$ série eu falava que queria ser administradora, não tinha dúvidas.

De acordo com a entrevistada Marthina, as incertezas inerentes à própria idade fizeram com que a decisão fosse tomada com o auxílio da família: "Foi muito por influência da família mesmo. É aquela coisa: não sei o que fazer, vou por aqui que também me dá várias chances, várias possibilidades, e foi mais ou menos por aí."

Um dos fatores determinantes para que a entrevistada Hannah escolhesse seu curso de graduação foi o fato de haver o curso na própria cidade:

Eu escolhi porque, então, eu já tinha ideia de fazer Direito e na minha cidade tinha faculdade, a universidade que proporcionou eu fazer a escolha pelo curso de Direito, então pude me manter na minha cidade, fazer estágio no escritório de advocacia e estudar à noite.

Todos os entrevistados foram enfáticos ao salientarem que a pouca idade dificultou bastante o processo de escolha. Essa insegurança se mostrou tanto nos testes vocacionais feitos como na existência de dúvidas entre várias opções de cursos.

\section{- A influência da família na escolha da carreira}

A família desempenha um papel de extrema importância em diversas esferas da vida de uma pessoa. Conforme já mencionado, Santos (2005) explica que ela influencia fortemente no projeto de vida de um indivíduo porque, normalmente, é no próprio núcleo familiar que o projeto se inicia e é por intermédio dele que o jovem "sai" em busca da realização de seus "sonhos". Quando questionada acerca da participação da família nesse processo, a entrevistada Cecília ponderou que:

Os meus pais em conversas comigo diziam que eu precisava olhar o mercado de trabalho. Administração é uma opção boa, Direito também. O meu pai dizia: 
vai abrir um leque pra fazer concurso, para tu advogar, para várias coisas. O pai me falava muito para fazer Direito. Tanto que depois o meu irmão passa em Direito na UFSM, então ele foi suprido por isso, mas eu não queria muito. E aqui eu tinha apoio desses meus tios maternos para estudar, para fazer cursinho, para me dedicar, para estudar numa federal. Eu sentia muito essa cultura de conseguir estudar na federal, né? E aí eu tinha um diálogo muito grande com esses tios aqui da parte da minha mãe.

De acordo com Filomeno (2003), quando o indivíduo decide seguir uma profissão, levará consigo todas as normas, os mitos, as expectativas que foram incutidas dentro do grupo familiar. Durante as entrevistas, foi possível perceber que a maioria dos entrevistados teve a escolha da carreira modelada pelo convívio familiar. Tamanha é a influência que a família exerce que a entrevistada Aimêe disse que:

O pai e mãe influenciaram no sentido daquilo que eles achavam que não seria bom. Tanto que Bioquímica acabou sendo descartado por isso, mas dito isso eles sempre deram muita autonomia para mim e para os meus irmãos. Às vezes eu até brinco dizendo que deram autonomia até demais. Então escolhido o percurso, eles aceitaram. Tirando aquela questão da preocupação com a Bioquímica, que daí eles foram muito enfáticos. Dali para frente, assim, participavam das ansiedades, conversavam, apresentavam argumentos, mas jamais impuseram um caminho. O pai sempre teve uma preocupação muito grande de: escolhe uma profissão que te dê uma renda tranquila, né? E aí ele sempre sinalizou: olha, talvez fosse interessante ser servidor público e coisa e tal. Mas mesmo vir para UNIPAMPA, trabalhar como Servidor Público Federal na área da docência foi uma oportunidade que surgiu e que eu aproveitei. Cavalo encilhado e deu certo e vamos lá.

As reflexões feitas pela entrevistada supracitada convergem com o pensamento de Almeida e Melo-Silva (2011, p. 82) sobre a influência da família nas ações objetivas e práticas, exemplificadas pelas intervenções dos pais, proporcionando: diálogos/ações que facilitem a exploração vocacional, apoio monetário, formação educacional; assim como influências de ordem subjetiva, por vezes inconscientes, como apoio, reprovação das escolhas, expectativas em relação a resultados, entre outras. Todas essas variáveis de influência possibilitam ou limitam o processo de escolha da carreira.

Quando questionados acerca de como se sentiram com a participação da família no processo de escolha de carreira, todos os entrevistados salientaram que a participação do núcleo familiar nesse processo de decisão é de suma importância. A entrevistada Aimêe afirmou que o processo de escolha da carreira é feito, normalmente, quando as pessoas ainda não possuem grande maturidade, em função da pouca idade, e por isso uma participação ativa da família é essencial:

$\mathrm{Eu}$ acho que na época de adolescente eu queria que eles participassem mais. No sentido de que a gente é muito novinho para decidir alguma coisa com 16, com 15, 16, 17 anos. Por outro lado, olhando para trás agora, eu acho que foi legal ter feito dessa forma, porque a decisão foi minha. Certo ou errado. Podia ter ido por outros caminhos? Podia. Mas sempre que a gente coloca: e se? E se monte de coisa. Então, eu não tenho queixa em relação à forma como eles interagiram comigo nesse processo e acredito que nem os meus irmãos tenham algum tipo de reclamação. E deu certo e vamos lá!

Embora a influência da família seja importante no processo de escolha da carreira, muitas vezes ela acaba não sendo tão salutar, pois pode pressionar psicologicamente os indivíduos. A entrevistada Cecília mencionou que: 
Era legal essa conversa, essa interação, como eu te contei, né? Dois anos de cursinho, isso era frustrante pra mim, ter que chegar ao final do ano e fazer vestibular na época e não passar. Encontro de final de ano, férias, toda família. Mesmo durante o ano quando de Santa Maria vinha para casa. E "como é que tá os estudos?" Sabe, é uma pergunta que não tem resposta. Eu estou estudando, sabe? Já esses meus tios (tios paternos) não ficava muito assim. Eu me sentia um pouco pressionada, sim! Acontece a pressão e tem sim.

Por causa dessa importância familiar, os indivíduos podem se sentir pressionados para fazer suas escolhas de acordo com as expectativas da família. Segundo o entrevistado Charles Darwin:

Na verdade não, eu não me lembro de muita participação, é uma coisa que a gente reflete que poderia ter ser melhor trabalhado assim com os filhos, então nunca me lembro de ter uma conversa assim, um momento de discutir profissão, discutir o futuro, discutir qual as principais áreas de atuação do tipo de profissional, de outro para que a gente pudesse tomar uma decisão. Então a gente tem agora filhos, fico pensando quando for a época delas escolherem... porque a gente tem duas meninas, né? Então quando for a época das meninas, vamos sentar para conversar: olha minha filha essas são as profissões e são assim desse tipo. Então eu me lembro que a minha escolha foi muito mais por esse ambiente que estava na época.

Segundo Luft, Boaventura e Colombo (2015), os adolescentes demonstram possuir uma desinformação no que tange à carreira e ao mercado de trabalho. Desse modo, quando a família não participa diretamente no processo de decisão, o indivíduo acaba encontrando maiores dificuldades quando chega o momento de escolher o que fazer.

\section{- Carreira docente}

Todos os entrevistados compartilharam suas experiências sobre o processo de decisão para se tornarem docentes e o que os auxiliou nisso. Percebeu-se que diversos foram os fatores intrínsecos e extrínsecos que os conduziram até a docência, não sendo possível apontar apenas um fator determinante para essa escolha. A entrevistada Princesa Sophia disse:

Quando eu comecei a fazer Direito, eu acho que também desde aquilo que a gente comentou, desde pequenininha, né? Sempre dava aula, o quadro negro lá em casa... E eu sempre gostei dessa parte da docência. Aí, então, na verdade tudo foi conspirando, né? Eu gostava e eu não tinha perfil, não tenho nem de estudar, de ficar em casa estudando para concurso... Então eu pensava assim: eu me graduando, eu fazendo mestrado, doutorado. Eu vou sair doutora, o esforço é meu, eu consigo fazer uma tese, eu entendia que eu tinha capacidade para isso. E o concurso eu podia estudar, estudar, estudar e talvez nunca obter êxito. Porque o concurso são várias variáveis, né? Além do estudo, tem que tá tranquila na hora da prova, tu tem que ser uma pessoa um pouco esperta assim, para fazer questões e reconhecer. E eu nunca gostei muito de ficar assim, 6-7 horas estudando. Sabe aquela coisa de não ter muita vida, quem faz concurso, geralmente concurso de níveis maiores, tem que abdicar muita coisa. E então aí eu fui indo pra esse lado. E aí depois, quando eu conheci o meu esposo, ele também tinha essa mesma vontade. E daí meu sogro conhecia uns contatos assim, pra gente fazer doutorado na Espanha e eu fui. Então foi tudo conspirando para isso, eu gostava da área, gostava da docência e daí fui 
encontrando no meu caminho outras pessoas que também gostavam. E aí foi tudo bem mais natural do que eu pensava que fosse.

A entrevistada Hannah salientou que a escolha pela carreira docente se deu naturalmente, pois o ambiente em que ela estava inserida acabou sendo o responsável por modelar a decisão:

Quando eu saí da graduação, eu já fui fazer especialização. E aí já gostei, fui muito estimulada pelos professores. Daí o primeiro TCC que eu fiz foi na especialização. Gostei do ato da defesa, de ser orientada por um professor e aí já comecei a dar aula. Passei no concurso para dar aula, tinha 24 anos e já estava no mestrado, então não desacelerei a carreira, né? Fui fazendo uma etapa após a outra, concluindo e ingressando. Terminei o mestrado, comecei doutorado. E aí depois de concluir o doutorado que deu a oportunidade deste concurso.

Conforme Deimling e Reali (2017, p. 7), a escolha pela docência é influenciada pelas experiências acadêmicas, pessoais e profissionais vivenciadas antes e depois da formação. Todos os entrevistados mencionaram que foi a totalidade das experiências que possuíam e o ambiente em que estavam inseridos o que acabou conduzindo cada um até a docência.

Outro aspecto analisado foi a participação dos familiares no processo de escolha da docência. A entrevistada Marthina mencionou a importância que seus pais tiveram quando a decisão por essa carreira foi tomada:

Quando passei na seleção do mestrado, daí eu me demiti da empresa da família. Pra o meu avô foi um choque, o que é que tu quer? Agora que tu veio, agora que tu tava aqui, tu vai? Várias pessoas me julgaram muito por isso, né? Mas a minha mãe sempre me deu apoio assim. Minha mãe e meu pai sempre acharam que eu tinha que escolher, se eu tinha estado lá, tinha provado e não tinha me achado, me encontrado. Que eu tinha que buscar ser feliz onde eu quisesse, onde eu achasse que tinha que trabalhar. E tá e eles me apoiaram muito, financeiramente falando também, em relação ao mestrado. No primeiro ano não teve bolsa, mas foi bom porque foi bem na época que [minha] irmã foi estudar em Santa Maria, então foi quase que um alívio para os meus pais. Então já tinham que pagar pra minha irmã mesmo, então eu já vou no pacote. E daí depois mestrado, eu comecei a dar aula particular e daí não voltei mais para o mercado assim, sem ser esse mercado acadêmico. E aí passei no concurso aqui, passei no do IFSul. E aí me achei, né?

Muitas vezes, indivíduos sofrem retaliações no núcleo familiar devido à decisão tomada ser incompatível com a expectativa gerada pela família. Conforme Neuburger (1999), membros de um grupo podem rejeitar certos comportamentos de outros membros do mesmo grupo por considerarem-nos "indignos" do grupo familiar.

O entrevistado Peter Quill destacou a importância que sua família desempenhou ao oferecer suporte financeiro enquanto ele concluía seus estudos:

Eu não trabalhava e assim, o que eu digo hoje ninguém aceita assim, né? Eu fui até o mestrado assim. Que no mestrado eu fui trabalhar em uma indústria e eu percebi que se eu continuasse a trabalhar na indústria eu não ia conseguir terminar o mestrado. E eu precisei escolher e eu escolhi ficar no mestrado. E eu falei com o pai, olha eu estou voltando pra casa e ele me disse assim: "um prato de comida não vai faltar." Só que eu já estava com 24 anos, para mim foi uma derrota muito grande. Mas eu preciso fazer isso, sabe? De não ter R $\$ 20,00$ pra pegar o ônibus e comer. Mas eu preciso terminar o mestrado.

O indivíduo, geralmente, busca apoio inicial na família. Santos (2005) afirma 
que os pais, na maior parte das vezes, são os responsáveis por custear os valores referentes à graduação. Por essa razão, normalmente, é na família que o indivíduo encontra suporte financeiro e emocional para executar, desenvolver e realizar seu projeto.

Quando questionados acerca da definição que davam para sua situação profissional, todos os entrevistados disseram estar satisfeitos com a profissão que escolheram. Hans Morgenthau afirmou:

Olha eu acho que ela é satisfatória, financeiramente é boa. Eu acho que em profissão ela é boa também. Eu acho que aqui, eu sou muito feliz na Unipampa, sempre fui, eu já estou há oito anos aqui. Infelizmente, eu acho que a Unipampa chega num teto do que você pode fazer como docente. Então, por mais que sejam muito interessantes os trabalhos aqui que a gente faz, em especial com os alunos, por ser uma universidade que, por exemplo, aqui no campus não tem muitas pós-graduação, não tem possibilidade da gente fazer projetos mais abertos, mais extensos. Isso é às vezes mais complicado. Na relação professoraluno e meus projetos aqui, eu diria que estou realmente, plenamente satisfeito. Em relação a possibilidades de crescimento e quando a gente fala de crescimento no setor público, você deve saber, não é maior salário, porque não vem maior salário, mas é você poder fazer mais coisa, isso de fato eu acho que é um pouco limitado na Unipampa, infelizmente. Não na perspectiva do aluno, mas na perspectiva do professor.

O entrevistado Charles Darwin ressaltou estar plenamente satisfeito com a carreira que escolheu e com a Instituição de Ensino em que trabalha:

Eu me sinto feliz assim. Sou um cara que adoro dar aula, tipo para mim cada aula é um momento bacana, eu saio da aula e fico feliz assim da aula que a gente dá e penso a essa coisa dá pra gente melhorar. Eu acho que a Unipampa ela é diferente de todas as universidades. Uma universidade nova, chegava e tinha que fazer tudo assim. Então eu cheguei na Unipampa e na outra semana, eu me lembro que já estava em uma comissão que tinha que definir regras, não tinha o regulamento. Então a gente começou a fazer tudo, se construiu a universidade. E além disso os alunos, apesar de terem assim, limitações, obviamente por questão de seleção, as universidades mais tradicionais têm alunos, talvez, com uma base melhor, mas a força de vontade e a disposição dos alunos, a diversidade dos alunos, a valorização e o reconhecimento que os alunos daqui dão pra isso, para esse ensino, é algo que me deixa super gratificado assim, eu não sairia cedo. Isso me deixa feliz, de saber que pode ajudar um pouquinho na formação das pessoas, né? No desenvolvimento da região, que a gente vai nas formaturas e ver, né? Agora teve formatura e a gente foi, ver a alegria daquelas pessoas de ter aquele título, de mudar as vidas daquelas pessoas simples, que nunca teriam, por exemplo, um curso superior, né? Não só uma profissão, mas a cidadania, a forma de pensar, de raciocínio, de ser mais questionador, de ver as qualidades de outra forma. Isso também me deixa mais assim gratificante da tarefa de ser professor. E aí eu acho que é um momento interessante, apesar de todas as dificuldades que a gente tem, é isso que me deixa mais feliz assim. É esse poder da educação.

A entrevistada Maria enfatizou que o ambiente universitário possibilita o trabalho frequente com novos projetos:

Olha, se fosse em uma única palavra, seria realizada. Eu gosto muito assim, gosto muito de dar aula. Eu gosto muito do ambiente da universidade, eu acho 
que ele é um ambiente que te permite pensar, refletir. É um ambiente que possibilita trabalhar com a crítica, né? Não somente com a questão mais usual, uma questão mais tarifeira e também ele é um ambiente que te dá uma flexibilidade, porque assim a cada semestre a gente tem uma turma nova, desafio novo. E a gente pode propor projetos novos na área de ensino, pesquisa e extensão, então isso faz com que cada dia, cada semestre, cada ano seja diferente. Então, assim, eu vejo alguns amigos que têm algumas profissões que são mais rotineiras, reclamando da rotina. Eu acho que o legal do trabalho da universidade é justamente ele ser o oposto disso, ele possibilitar, né? Eu estou aqui refletindo sobre minha própria vida nesse momento, se eu não tivesse na universidade não teria essa oportunidade.

Somente após a compreensão das motivações que levam um indivíduo a escolher uma carreira, bem como da influência dos fatores intrínsecos e extrínsecos, é que o profissional consegue ter uma compreensão mais apurada se a escolha feita foi a mais ajustada. Segundo Valle (2006), para se entender as escolhas dos indivíduos, é necessário considerar as estruturas do campo profissional e toda a lógica de transformação e funcionamento da profissão.

A escolha da carreira de docente universitário se afasta da realidade das demais profissões. Pois, em um primeiro momento a escolha se dá por uma profissão de formação através da graduação que pode leva-lo ou não para a docência. A escolha pela docência vem em um segundo momento, dentro do processo de formação e a escolha pelo ambiente acadêmico. Salienta-se que nenhum dos entrevistados demonstrou inclinação para a docência a princípio. Por vezes, a decisão ocorreu nas fases finais da graduação e, em grande parte, após a sua conclusão. No entanto, independentemente de a escolha ser realizada durante a vida adulta, foi na família que os indivíduos encontraram suporte, seja emocional, seja financeiro.

- Genoprofissiograma

Com base nas respostas obtidas, foi possível apontar os membros mais significativos da família para cada entrevistado. Para melhor visualização, as informações dos indivíduos foram separadas do desenho do genoprofissiograma, sendo destacados os graus de escolaridade e as profissões dos indivíduos mais significativos.

Após a elaboração do genoprofissiograma (Figura 1), foi solicitado que indicassem as pessoas mais relevantes em sua vida. A entrevistada Aimêe elencou seus pais, sua avó paterna, duas tias maternas e sua irmã. No entanto, especificamente no período da escolha profissional, os pais se mostraram com mais influência. Ambos estudaram até o Ensino Médio. A mãe da entrevistada foi operária em uma fábrica e, após um período, passou a se dedicar exclusivamente ao lar. O pai da entrevistada era militar, chegando a se tornar capitão do exército, essa formação do exército concedeulhe também o nível de graduado em Engenharia Civil. 


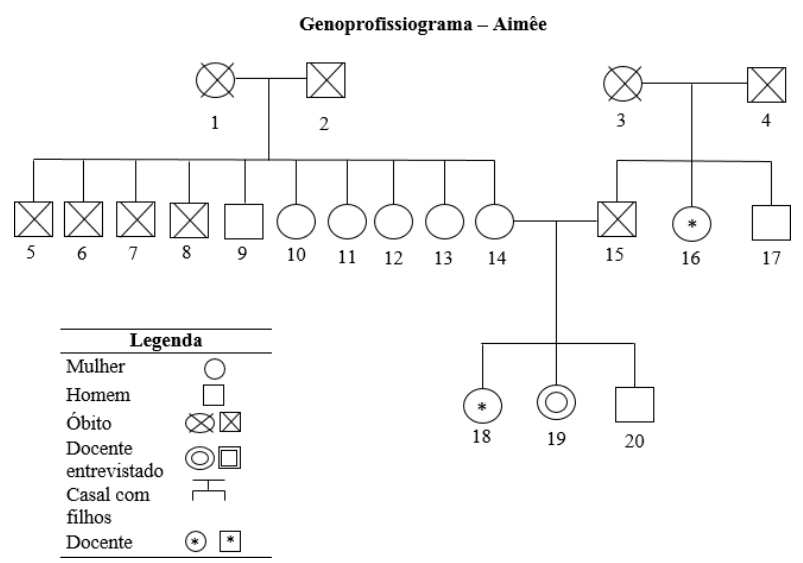

Figura 1. Genoprofissiograma: Aimêe.

Fonte: Elaborado pela autora.

Para a entrevistada Cecília, seus pais, seu irmão e seus tios maternos formam o grupo de pessoas significativas em sua vida. No período de escolha profissional, existiu uma grande influência dos pais e dos tios maternos, todos possuem Ensino Superior. A mãe da entrevistada tem pós-graduação em Psicopedagogia e atuou como professora escolar até sua aposentadoria. O pai detém o título de mestre em Ciência da Computação, é professor e empresário. Percebeu-se na escolha de Cecília uma grande atuação dos mitos familiares. Ela afirmou:

$\mathrm{Eu}$ sabia desde cedo que meus tios saíram de casa para estudar, então que eu iria seguir o que os meus tios sempre fizeram. Com 17 anos saí de casa e nunca mais voltei. Fui estudar, fazer cursinho, comecei a faculdade e tal.

Isso corrobora com a trama mítica retratada por Paccola (1994), que diz que os membros da família possuem lealdades invisíveis nas quais se espera que todos assumam um determinado compromisso. Apesar de não haver cobrança explícita para que a entrevistada agisse de tal maneira, ela sabia o que era esperado dela por seus familiares.

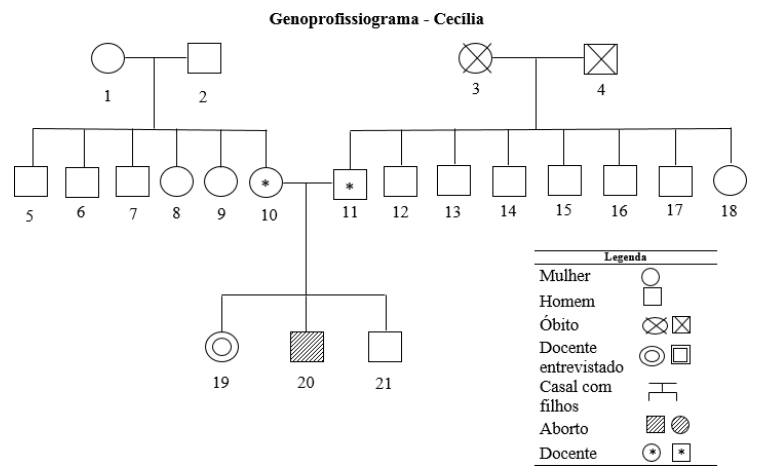

Figura 2. Genoprofissiograma: Cecília.Fonte: Elaborado pela autora.

O entrevistado Charles Darwin vem de uma família em que a grande maioria dos membros é de professores. Isso reforça a pesquisa de Fanfani (2005), que reconhece a carreira de professor como uma das profissões que possuem tendência a serem transmitidas entre as gerações. Como resposta ao questionamento feito ao término da elaboração do genoprofissiograma (Figura 3), ele enfatizou seus pais como as duas pessoas mais relevantes. Durante a escolha da carreira docente, sua irmã também desempenhou um papel importante. Todos os membros citados atuam como 
docentes. A mãe do respondente é graduada, o pai possui título de mestre e, por fim, sua irmã é doutora.

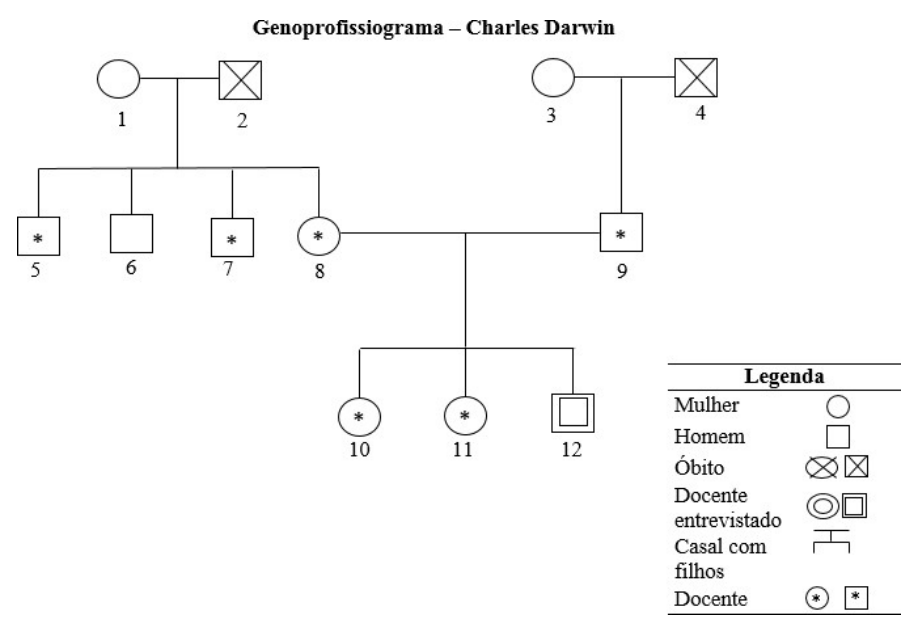

Figura 3. Genoprofissiograma: Charles Darwin. Fonte: Elaborado pela autora.

Considerando a árvore genealógica desenhada (Figura 4), a entrevistada Hannah destacou seus pais e seus irmãos, mais especificamente seus pais durante a escolha da carreira. Pois, segundo sua opinião, eles disponibilizaram os meios necessários para que ela pudesse seguir a profissão desejada. Sua mãe é professora estadual e possui Ensino Superior, enquanto o pai estudou até o Ensino Fundamental e é empresário.

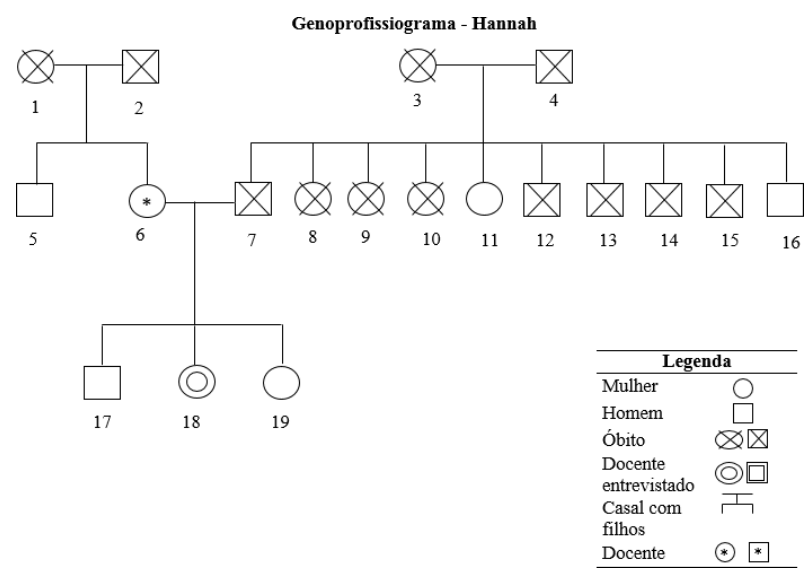

Figura 4. Genoprofissiograma: Hannah Fonte: Elaborado pela autora.

Conforme pode ser observado na Figura 5, a mãe, o pai e o irmão do entrevistado Hans Morgenthau foram determinados como os mais significativos. Uma característica evidenciada pelo entrevistado foi o fato de ter sido criado em um ambiente com muito estímulo para a leitura. Ele acredita que isso deriva da formação (mãe com Ensino Superior e pai pós-doutor) e profissão dos pais, ambos professores. 


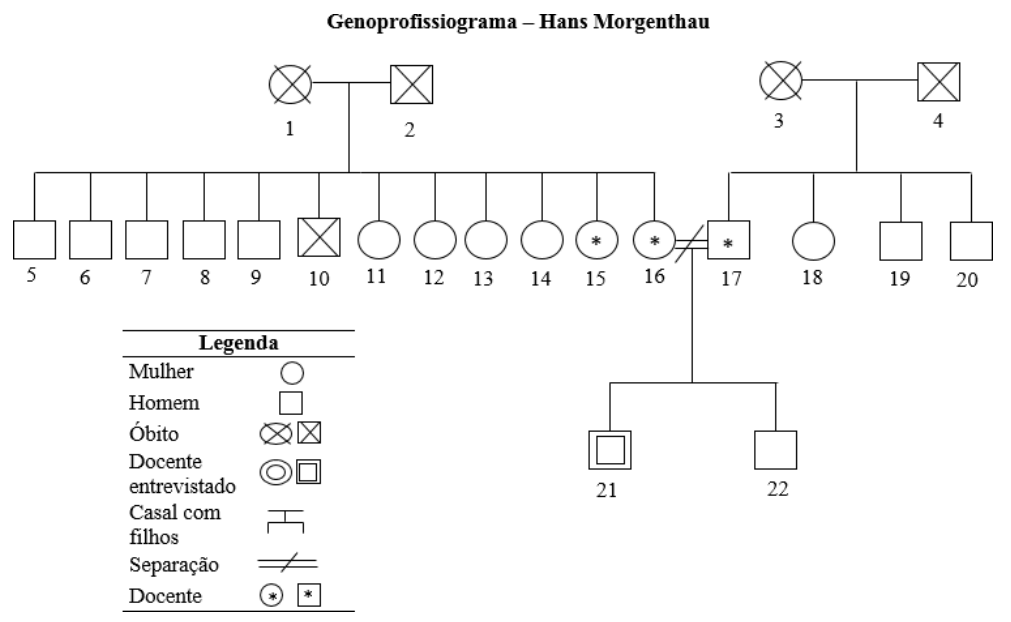

Figura 5. Genoprofissiograma - Hans Morgenthau. Fonte: Elaborado pela autora.

A entrevistada Maria elencou os pais e a irmã como importantes em sua vida, isso também se tornou evidente na escolha da carreira, que contou com o apoio desses membros tanto em aconselhamentos e orientações como na oferta de condições para ela conseguir percorrer o caminho escolhido. Observa-se que a mãe da entrevistada é professora, com Ensino Superior, o pai é empresário, com Ensino Médio, e sua irmã é médica pós-graduada. A árvore genealógica pode ser vista na Figura 6.

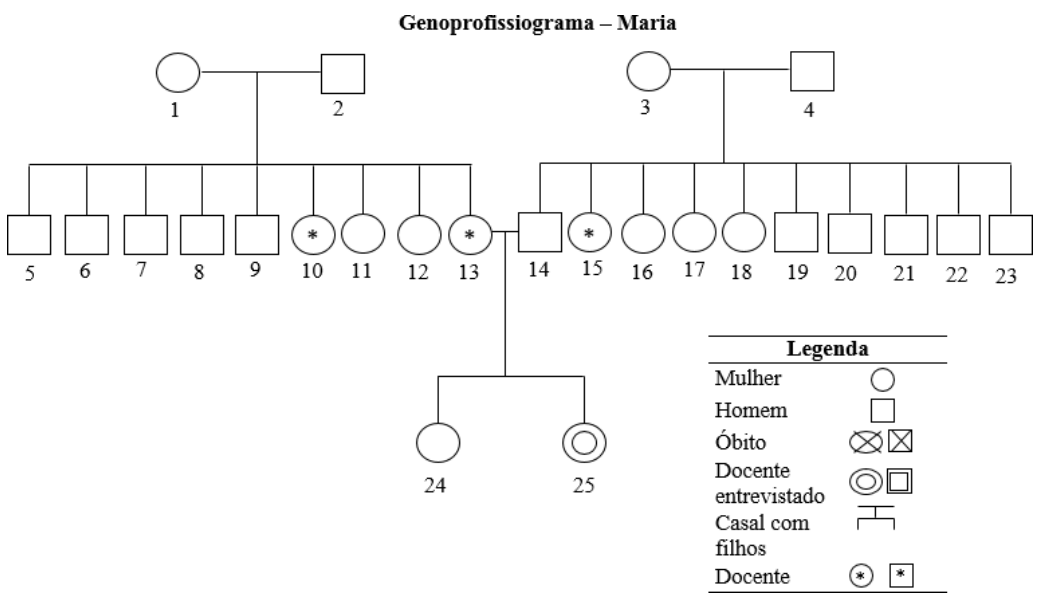

Figura 6. Genoprofissiograma: Maria. Fonte: Elaborado pela autora.

Em detrimento das circunstâncias de trabalho de seus pais, a entrevistada Marthina explicou que seus avós maternos desempenharam um papel muito importante em sua criação, tornando-se significativos por essa razão. Entretanto, ela não limitou o destaque de seus pais. Para a construção de sua carreira, estritamente, a atuação da mãe se sobressai, pois ela introduziu a entrevistada à docência, por meio de um convite para lecionar em um curso técnico. No primeiro ano de mestrado, houve o auxílio financeiro prestado por seus pais. Sua mãe é empresária, atualmente aposentada, cursou três graduações, sendo Administração, Psicologia e Contabilidade. Seu pai também é empresário aposentado e tem graduação em Direito. 


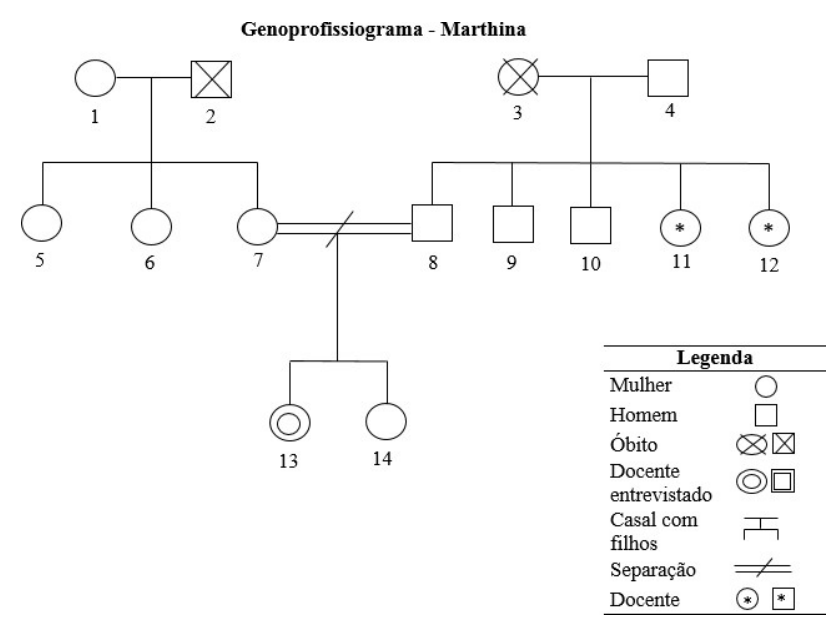

Figura 7. Genoprofissiograma: Marthina.

Fonte: Elaborado pela autora.

Para o entrevistado Peter Quill, seus pais e sua avó materna "representam até hoje exemplos a serem seguidos". Durante a escolha da carreira, a influência ocorreu de modo mais direto pelos pais, pelo apoio financeiro. A mãe do entrevistado, inicialmente, opôs-se ao filho estudar em determinada universidade que havia sido escolhida. O pai exerceu por anos um cargo de funcionário público e não chegou a concluir o Ensino Fundamental, enquanto a mãe se dedicou exclusivamente ao lar e possui Ensino Médio incompleto.

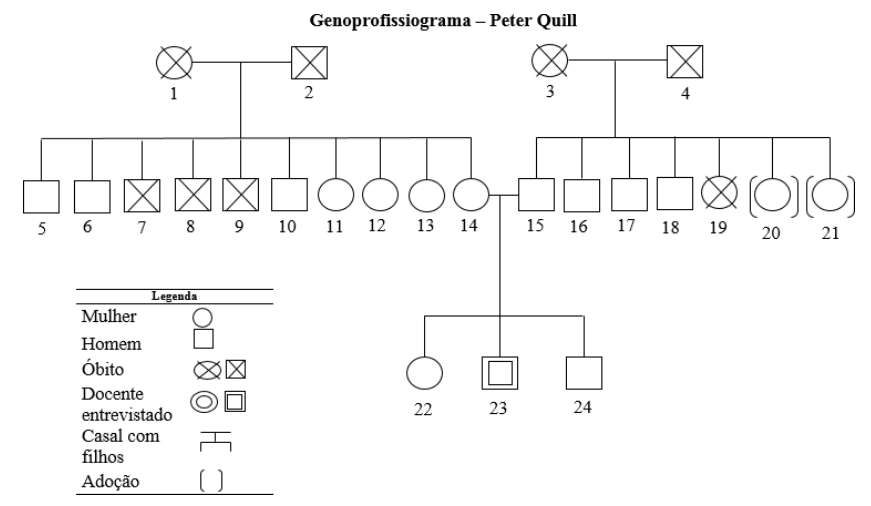

Figura 8. Genoprofissiograma: Peter Quill.

Fonte: Elaborado pela autora.

Para a entrevistada Princesa Sophia, os membros mais relevantes de sua família foram seus pais. Sua mãe, professora, sempre incentivou a leitura e demonstrava preferência pelo curso de Odontologia, levando a entrevistada a prestar o primeiro vestibular para esse curso, sem aprovação. Desse modo, seus pais the ofereceram duas opções: dar início a um curso pré-vestibular ou escolher outro curso de graduação. Princesa Sophia optou por cursar Direito. O pai atuava como comerciante e estudou até o Ensino Fundamental, ao passo que a mãe era pósgraduada. 


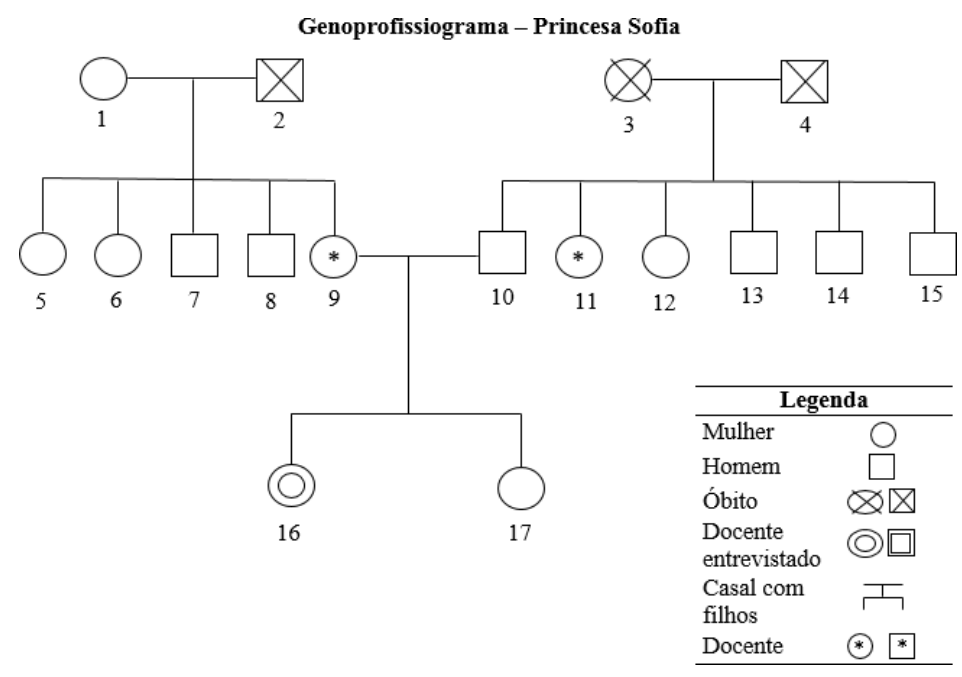

Figura 9. Genoprofissiograma: Princesa Sofia.

Fonte: Elaborado pela autora.

Após o desenho do genoprofissiograma, foi possível notar um aumento significativo no grau de escolaridade entre as gerações. Também se pôde observar todas as profissões dos integrantes da família dos entrevistados. Dentre as nove famílias representadas, oito possuíam no mínimo um membro que exercia docência, lecionando desde a pré-escola até o Ensino Superior.

Os resultados assemelham-se à pesquisa realizada por Fanfani (2005), que afirma que a carreira de professor é fortemente hereditária, pois metade dos participantes mencionaram possuir algum familiar com a mesma profissão. Terminada a análise dos dados, seguem, na sequência, as considerações finais desta pesquisa.

\section{Considerações finais}

Com base no objetivo geral deste estudo, que foi a investigação da influência que a árvore genealógica profissional tem na escolha da carreira de docentes, e a partir da análise dos dados obtidos, conseguiu-se verificar a importância desempenhada pela família no processo de escolha da carreira.

Por meio das entrevistas realizadas, percebeu-se o quanto a família se configura em um dos principais fatores que auxiliam ou obstaculizam como a escolha da carreira é realizada, uma vez que todos os indivíduos pertencem a uma família, que possui características distintas e uma história singular. O presente estudo concentrou-se em analisar, majoritariamente, como se deu o processo de escolha da carreira docente, em virtude da relevância que a profissão possui na construção dos saberes de toda a sociedade.

Apurou-se que nenhum dos entrevistados planejava, inicialmente, tornar-se um docente, todavia os caminhos para a docência se formaram a partir da aproximação com o mundo acadêmico. Não se pôde destacar uma razão específica para a escolha da carreira, mas se confirmou que inúmeros fatores intrínsecos e extrínsecos acabaram modelando esse processo de decisão. O planejamento profissional foi feito após os entrevistados ponderarem elementos como: empregabilidade, contexto em que viviam, grau de aproximação com a carreira, habilidades, sua personalidade e expectativas em relação ao futuro.

Verificou-se que, em todas as entrevistas, os principais influenciadores do processo de escolha da carreira foram os pais. A relevância dos pais foi observada no suporte financeiro e emocional que deram aos seus filhos, por vezes arcando com os 
custos associados ao curso de graduação ou oferecendo orientação acerca das profissões.

Constatou-se também que oito dos nove entrevistados possuem familiares que desempenham a profissão de educadores. Apenas um dos entrevistados não possui nenhum professor no seu núcleo familiar. Tal situação só foi visualizada pelos entrevistados após a construção do genoprofissiograma. Nesse sentido, a partir desse método foi apurada a compreensão de que, ainda que inconscientemente, o fato de terem professores em sua família acabou influenciando na decisão da carreira seguida.

Mostrou-se como limitação da pesquisa não ter sido alcançada a quantidade inicialmente estabelecida de docentes entrevistados, em virtude da falta de disponibilidade de todos. Em comparação à população de docentes da Universidade Federal do Pampa, campus Santana do Livramento, o grupo respondente pode ser considerado pequeno, constituindo outra limitação.

Para pesquisas futuras, recomenda-se que os temas abordados com brevidade neste estudo sejam estudados com maior profundidade, especialmente o aumento no grau de escolaridade entre as gerações e as causas para esse fato. É extremamente salutar para o indivíduo conhecer os elementos que compõem o processo de escolha de sua carreira, posto que, a partir disso, pode-se pensar em alternativas eficientes para atingir seus objetivos profissionais.

\section{Referências}

Aguiar, Wanda Maria Junqueira de (2006). A escolha na orientação profissional: contribuições da psicologia sócio-histórica. Psicologia da Educação, 23, 1125. Recuperado de http://pepsic.bvsalud.org/pdf/psie/n23/v23a02.pdf.

Almeida, F. H., e Melo-Silva, L. L. (2011). Influência dos pais no processo de escolha profissional dos filhos: uma revisão da literatura. Psico-USF, 16(1), 75-85. http://dx.doi.org/10.1590/S1413-82712011000100009.

Almeida, P. C. A., Tartuce, G. L B. P., e Nunes, M. M. (2010). Alunos do Ensino Médio e atratividade da carreira docente no Brasil. Cadernos de Pesquisa, 40(140), 445-477. http://dx.doi.org/10.1590/S0100-15742010000200008.

Bardin, L. (1977). Análise de conteúdo. Lisboa: Edições 70.

Boni, V., e Quaresma, S. J. (2005). Aprendendo a entrevistar: como fazer entrevistas em Ciências Sociais. Em Tese, 2(3), 68-80. https://doi.org/10.5007/\%25x.

Bueno, R. F. F (2013). Sistematização de um processo de consultoria de carreira do ponto de vista sistêmico: adaptação de instrumentos. São Paulo: PUC.

Creswell, J. (2014). Investigação qualitativa e projeto de pesquisa: escolhendo entre cinco abordagens. $3^{\mathrm{a}}$ ed. Porto Alegre: Penso.

Deimling, N. N. M., e Reali, A. M. M. R. (2017). O programa institucional de bolsa de iniciação à docência, as escolhas profissionais e as condições de trabalho docente. Educação em Revista, 33(3, e143999), 1-24. ttp://dx.doi.org/10.1590/0102-4698143999.

Fanfani, E. T. (2005). La condición docente. Buenos Aires: Siglo Veintiuno Editores.

Filomeno, K. (2003). Mitos familiares e escolha profissional: uma proposta de intervenção focada na escolha profissional à luz de conceitos da teoria sistêmica (Dissertação de Mestrado). Universidade Federal de Santa Catarina, Florianópolis. 
Freire, P. (2000). Pedagogia da indignação: cartas pedagógicas e outros escritos. São Paulo: Editora UNESP.

Freitas, P. M. L., e Barbosa, T. P. (2006). $A$ escolha profissional e a influência da família. Revista Uningá, 10(1), 135-142. Recuperado de http://revista.uninga.br/index.php/uninga/article/view/525.

Gatti, B. A. (2012). Reconhecimento social e as políticas de carreira docente na Educação Básica. Cadernos de Pesquisa, 42(145), 88-111. http://dx.doi.org/10.1590/S0100-15742012000100007.

Gerhardt, T. E., e Silveira, D. T. (Org). (2009). Métodos de Pesquisa. Porto Alegre: Editora da UFRGS.

Gil, A. C. (2002). Como elaborar projetos de pesquisa. $4^{\mathrm{a}}$ ed. São Paulo: Atlas.

Krom, M. (2000). Família e mitos, prevenção e terapia: resgatando histórias. São Paulo: Summus.

Lakatos, E. M. e Marconi, M. A. (1999). Técnicas de Pesquisa. $4^{\text {a }}$ ed. São Paulo. Atlas S A.

Luft, H. M., Boaventura, J. M., e Colombo, S. C. S. (2015). Escolha profissional na adolescência: aspectos a considerar. In Lassance, M. C. P. Levenfus, R. S., e Melo-Silva, L. L (Org.). Orientação de carreira: investigação e práticas (pp. 17-28). Porto Alegre: Associação Brasileira de Orientação Profissional.

Minayo, M. C. (2002). Pesquisa Social: teoria, método e criatividade. Petrópolis, Vozes.

Neuburger, R. (1999). O mito familiar. Tradução de S. Rangel. São Paulo: Summus.

Nogueira, C. M. M. (2004). Dilemas na análise sociológica de um momento crucial das trajetórias escolares: o processo de escolha do curso superior (Tese de Doutorado). Universidade Federal de Minas Gerais, Belo Horizonte.

Nogueira, C. M. M., Almeida, F, J., e Queiroz, K. A. S. (2011). A escolha da carreira docente: complexificando a abordagem sociológica. Vertentes, 19(1), 1-20. Recuperado de https://ufsj.edu.br/vertentes/edicao_v._19_n._1.php.

Paccola, M. K. (1994). Leitura e diferenciação do mito. São Paulo: Summus.

Pinto, José Marcelino Rezende. (2009). Remuneração adequada do professor: desafio à educação brasileira. Revista Retratos da Escola, 3(4), 51-67. Recuperado de https://www.cnte.org.br/images/stories/2012/revista_retratosdaescola_04_2009 _remuneracao_adequada.pdf.

Raupp, F. M., e Beuren, I. M. (2006). Metodologia da pesquisa aplicável às Ciências Sociais. In Beuren, I. M. (Org.). Como elaborar trabalhos monográficos em Contabilidade: teoria e prática (pp. 76-97). $3^{\mathrm{a}}$ ed. São Paulo: Atlas.

Santos, L. M. M. (2005). O papel da família e dos pares na escolha profissional. Maringá: Psicologia em Estudo.

Schoen-Ferreira, T. H., Aznar-Farias, M., e Silvares, E. F. M. (2003). A construção da identidade em adolescente: um estudo exploratório. 
Estudos da Psicologia, 8(1) 107-15. http://dx.doi.org/10.1590/S1413294X2003000100012.

Soares, D. H. P. (2002). A escolha profissional do jovem ao adulto. São Paulo: Summus.

Thompson, J. B. (2011). Ideologia e cultura moderna: teoria social crítica na era dos meios de comunicação de massa. $9^{\mathrm{a}} \mathrm{ed}$. Petrópolis: Vozes.

Tonn, C. F., Geremia, H. C., e Schweitzer, L. (2015). Maturidade para escolha profissional e expectativas de alunos de cursos técnicos do PRONATEC. In Lassance, M. C. P., Levenfus, R. S., e Melo-Silva, L. L (Org.). Orientação de carreira: investigação e práticas (pp. 89-101). Porto Alegre: Associação Brasileira de Orientação Profissional.

Valle, I. R. (2006). Carreira do magistério: uma escolha profissional deliberada? Revista Brasileira de Estudos Pedagógicos, 87, 178-187. https://doi.org/10.24109/2176-6681.rbep.87i216.792.

Veriguine. N. R., Krawulski, E., D'Avila, G. T., e Soares, D. H. P. (2010). Da formação superior ao mercado de trabalho: percepções de alunos sobre a disciplina Orientação e Planejamento de Carreira em uma universidade federal. Revista Electrónica de Investigación y Docencia (REID), 4, 79-96., 79-96. Recuperado de https://revistaselectronicas.ujaen.es/index.php/reid/issue/view/88.

Data de recebimento: 08/11/2019

Data da revisão: $21 / 01 / 2020$

Data do aceite: $21 / 01 / 2020$ 